\title{
New Designs of Ceramic Hollow Fibres toward Broadened Applications
}

Melanie Lee, Bo Wang, K. Li, *

Department of Chemical Engineering, Imperial College London, London, SW7 2AZ, UK

*kang.li@imperial.ac.uk

\section{Abstract}

Three structural designs for ceramic membranes have been achieved for the first time through the co-extrusion of polymeric and ceramic layers. During co-extrusion, micro-channels are initiated due to the Rayleigh-Taylor instability and they propagate through the different layers. The polymeric layer(s) is then calcined off during the heat treatment step, which opens the microchannels and following sintering a ceramic membrane with open micro-channels ranging from a few to a few tens of micrometres in diameter can be formed. These long, straight and nontortuous micro-channels can be controlled to be open at any or all of the surfaces. Design 1 has open micro-channels passing through the entire membrane wall, Design 2 has a separation layer at the lumen and open micro-channels at the shell side, and Design 3 has open micro-channels from both lumen and shell sides sandwiching a separation layer of sponge-like structure. Aside from having much improved mass transfer property due to the reduced effective membrane thickness, they can be easily incorporated into hybrid systems with anticipated improvements in unit compactness and performance. The pure water permeation of Design 2 reached up to 159, $000 \mathrm{~L} / \mathrm{m}^{2} \mathrm{~h}$ bar with pore sizes in the micro-filtration range. The micro-channels are easily accessible from the shell/lumen side; therefore catalysts or adsorbents can be easily deposited into the micro-channels. Examples of possible applications include a high-efficiency dispersing device realised with Design 1; a gas chromatography column for gas separation with very low pressure drop realised with Design 2 and a highly compact membrane micro-reactor for consecutive reactions proposed with Design 3.

\section{Keywords: Asymmetric ceramic membranes, hollow fibre membranes, micro-channels}

*To whom the correspondence should be addressed.

Tel: +44 2075945676

Fax: +44 2075945676

E-mail address: kang.li@imperial.ac.uk 


\section{Introduction}

The combined phase inversion and sintering method is a promising method for creating ceramic membranes that have shown various advantages over traditional methods. Firstly, they can produce asymmetric membranes in a single step requiring one heat treatment session only, and secondly, the method is versatile and can be used to form a wide range of different membrane configurations: flat discs, hollow fibres, multi-channel monoliths, etc [1-4]. The ability to form finger-like micro-channels in the membranes due to interfacial instabilities not only reduces mass transfer resistance, giving rise to competitive pure water permeation fluxes, but also widens the possible applications of these ceramic membranes [4-11].

The majority of the ceramic membranes fabricated by this method in literature consist of dense inner and outer surfaces and regions of micro-channels, which may sometimes sandwich a layer of sponge-like structure. The surface with the smallest packing pore size would act as the separation layer. Hence, if the pore size of the separation surface meets separation requirements, the other surface or sponge-like layers do not offer any improvements in selectivity, but instead creates additional resistances to mass transfer. By eliminating the redundant dense surface and sponge-like layer, the pure water flux of the membranes can be dramatically increased [2]. Furthermore, the micro-channels are desirable crevices where catalysts or other active components can be deposited or coated to form hybrid systems $[1,12]$, but the existence of the dense surfaces prohibit access to these micro-channels unless solution techniques are employed. For flat disc membranes, it is very simple to mechanically open the micro-channels via sanding off the dense surface and/or the sponge-like layer. However, this is much more difficult to do in hollow fibre membranes. So far, research has been carried out to obtain openings on hollow fibre inner surfaces, and open micro-channels at the lumen side have been achieved in several studies by incorporating a solvent into the bore fluid $[3,13,14]$. This configuration has been shown to reduce the mass transfer resistance and thus substantially improve permeation fluxes. However, there may be applications whereby other configurations are desired, for example, open microchannels at the outer surface only, or open channels throughout the entire membrane crosssection. The flexibility of the combined phase inversion and sintering method means that the cross-sectional structure of hollow fibres can be designed and tailored as desired. In this study, three significantly different membrane cross-sectional structures with open micro-channels have been designed and fabricated via the co-extrusion of polymeric and ceramic layers. The coextrusion of multiple of layers has been used extensively in both polymeric and ceramic membranes, broadening their applications whilst reducing fabrication costs [15-18]. Different 
materials can be used in the different layers to increase the functionality of the membranes. Duallayered polymeric membranes have found use in applications such as pervaporation and membrane distillation and triple-layered membranes in solid oxide fuel cells $[19,20]$. However, the multi-layered membranes in literature are mostly entirely organic, or inorganic, and the fingerlike structures in these membranes are still enclosed inside the membranes. In this study, polymeric and ceramic layers were co-extruded, and following heat treatment the polymeric layer(s) are removed, leaving unique single-layered ceramic membrane structures. For the first time, ceramic hollow fibres with open micro-channels at the desired surface(s) have been formed in a single spinning step as shown in Figure 1 and their properties such as cross-sectional morphology, pore size distribution, mechanical stability and pure water flux were systematically investigated and their potential applications were discussed.

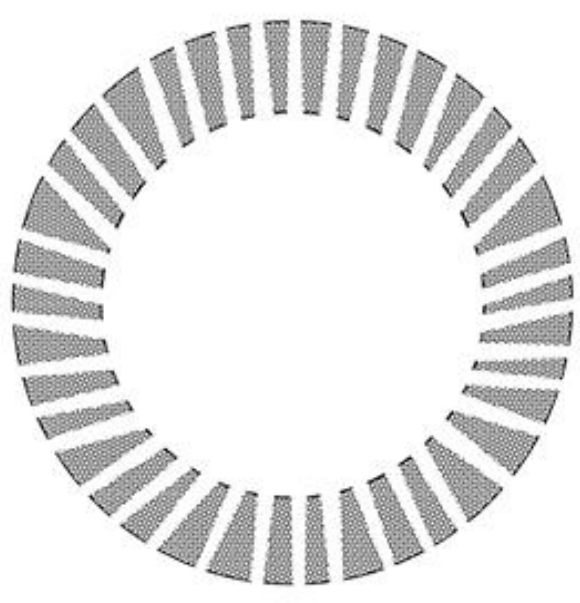

Design 1

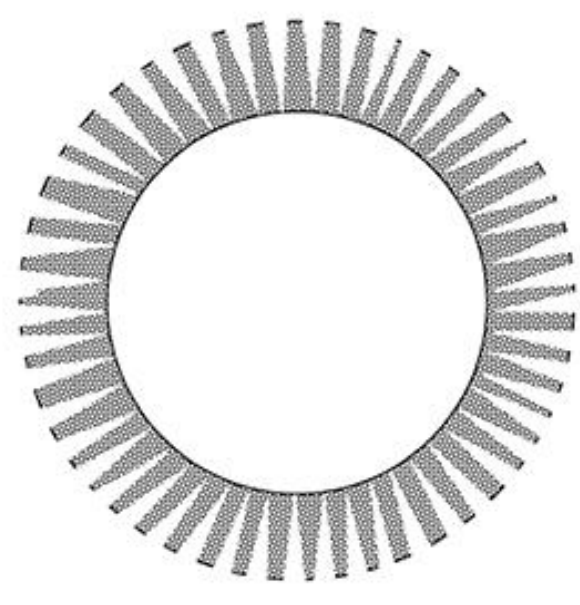

Design 2

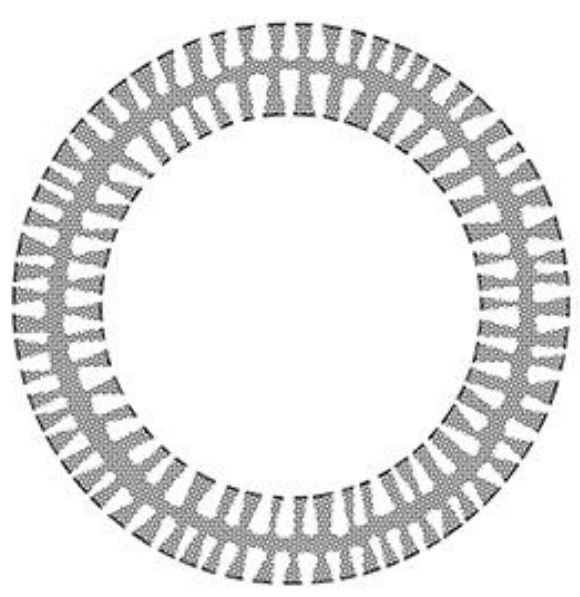

Design 3

Figure 1 Schematic of the three types of hollow fibre cross-section structural designs achievable through co-extrusion of ceramic and polymeric layers

\section{Experiments}

\subsection{Materials}

Aluminium oxide $\left(\mathrm{Al}_{2} \mathrm{O}_{3}\right)$ (alpha, 99.9\% metals basis, surface area $6-8 \mathrm{~m}^{2} / \mathrm{g}$, mean particle size (d50) 1 $1 \mu \mathrm{m}$, Inframat Corporation) was used as supplied. Polyethersulfone (PESf) (Radal A300, Ameco Performance, USA) was used as the polymeric binder. Dimethyl sulphoxide (DMSO, HPLC grade, VWR), N-methyl-2-pyrrolidone (NMP, HPLC grade, VWR), Triethyl phosphate (TEP, HPLC grade, Sigma Aldrich) were used as the solvents. Arlacel P135 (polyethylene glycol 30dipolyhydroxystearate, Uniqema) is used as the additive. De-ionized water and ethanol (HPLC grade, VWR) were used as the coagulants. 


\subsection{Fabrication of micro-structured alumina hollow fibre membranes}

The fabrication process is based on the phase-inversion technique used to prepare multilayer hollow fibres, whereby a ceramic suspension layer served as the precursor, and polymeric layers were used as sacrificial layer to generate the desired structures. A uniform suspension composed of ceramic particles, solvent and polymeric binder, as well as an additive acting as a dispersant, was prepared via ball milling, and its composition is listed in Table 1. The polymer dopes were prepared by mechanically stirring PESf in NMP under room temperature for $24 \mathrm{~h}$ for Designs 1 and 3, and PESf in TEP under $80^{\circ} \mathrm{C}$ for $48 \mathrm{~h}$ for Design 2 . The ceramic suspension was then degassed under vacuum with stirring to fully remove bubbles, and then transferred into a $200 \mathrm{~mL}$ stainless steel syringe that was controlled by a syringe pump (Harvard PHD22/200 HPsi and KDS410). The polymer dopes were left in an oven overnight at $80^{\circ} \mathrm{C}$ to degas and then transferred into a $100 \mathrm{~mL}$ stainless steel syringe controlled by another syringe pump. The ceramic suspension and polymer dopes were thus be extruded through the spinnerets shown in Figure 2, into the external coagulation bath. Meanwhile, DI water or a solvent and non-solvent mixture is introduced through the spinnerets via another syringe pump. The precursor hollow fibre membranes were removed from the external coagulant bath when phase-inversion was complete, and were dried and straightened at room temperature. They were then cut into the required length for subsequent calcination and sintering. Further details on the parameters of the fabrication process are listed in Table 1 and Table 2. For comparison, a conventional single-layer hollow fibre was also prepared, and the fabrication parameters are also included in Table 1 and Table 2.

Table 1 Composition of the 3 designs' precursor layers

\begin{tabular}{|c|c|c|c|c|c|c|c|c|}
\hline \multirow{3}{*}{ Layer } & \multicolumn{8}{|c|}{ Composition (\%) } \\
\hline & \multicolumn{2}{|c|}{ Design 1} & \multicolumn{2}{|c|}{ Design 2} & \multicolumn{2}{|c|}{ Design 3} & \multicolumn{2}{|c|}{$\begin{array}{c}\text { Common single layer } \\
\text { hollow fibre }\end{array}$} \\
\hline & NMP & 33.6 & DMSO & 33.6 & NMP & 33.6 & DMSO & 33.6 \\
\hline \multirow{3}{*}{$\begin{array}{l}\text { Ceramic } \\
\text { layer }\end{array}$} & Alumina & 60.0 & Alumina & 60.0 & Alumina & 60.0 & Alumina & 60.0 \\
\hline & PESf & 6.0 & PESf & 6.0 & PESf & 6.0 & PESf & 6.0 \\
\hline & A135 & 0.4 & A135 & 0.4 & A135 & 0.4 & A135 & 0.4 \\
\hline \multirow{2}{*}{$\begin{array}{c}\text { Polymeric } \\
\text { layer }\end{array}$} & NMP & 80.0 & TEP & 80.0 & NMP & 80.0 & \multirow{2}{*}{\multicolumn{2}{|c|}{ N.A. }} \\
\hline & PESf & 20.0 & PESf & 20.0 & PESf & 20.0 & & \\
\hline \multirow{2}{*}{ Bore fluid } & NMP & 70.0 & \multirow{2}{*}{ Water } & \multirow{2}{*}{100.0} & \multirow{2}{*}{ Water } & \multirow{2}{*}{100.0} & \multirow{2}{*}{ Water } & \multirow{2}{*}{100.0} \\
\hline & Ethanol & 30.0 & & & & & & \\
\hline
\end{tabular}




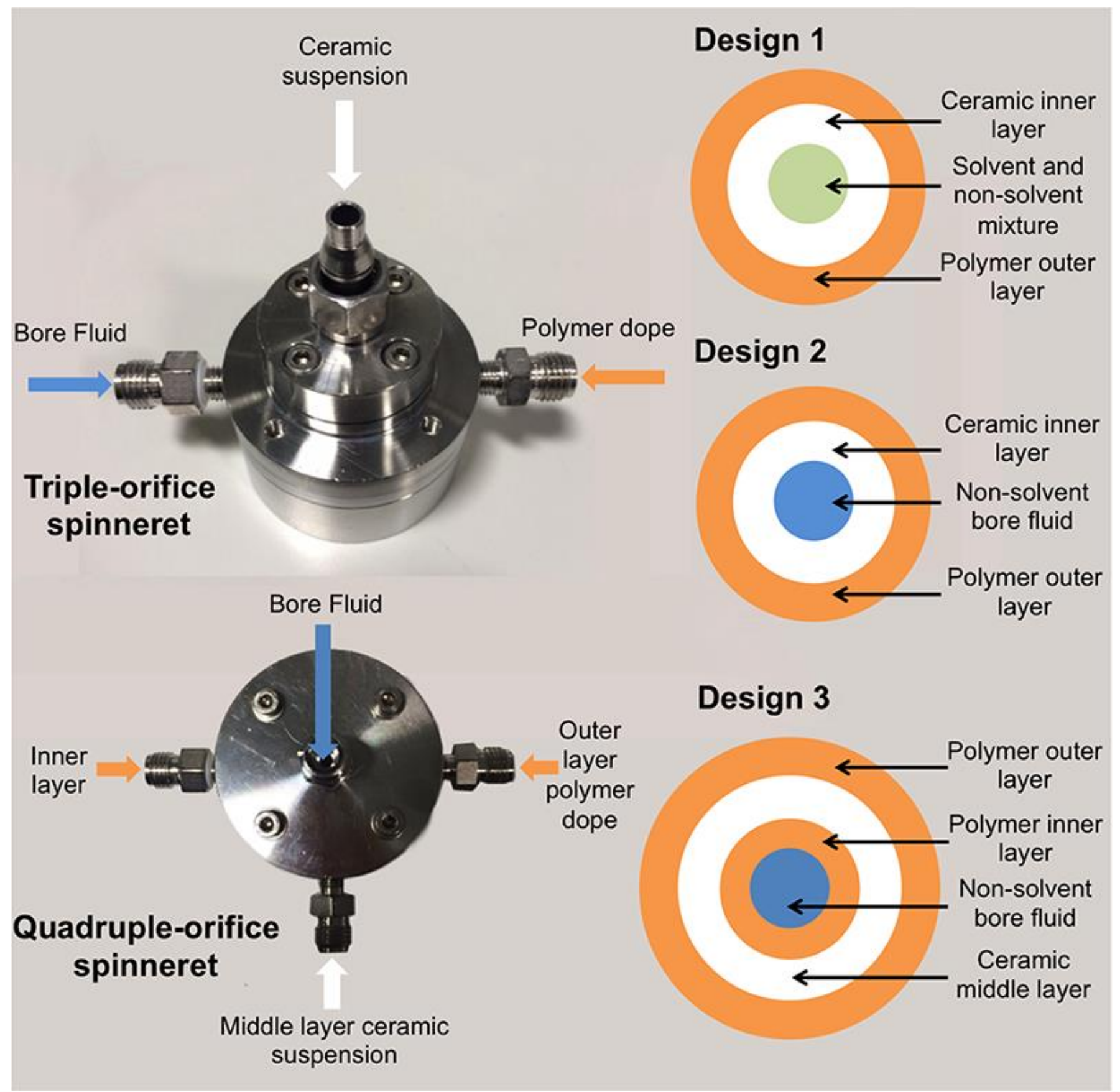

Figure 2 Photograph of the triple-orifice and quadruple-orifice spinnerets and schematic diagram of the orifice during spinning of the dual-layer and triple-layer hollow fibre precursors

Table 2 Spinning parameters used for the 3 designs

\begin{tabular}{|c|c|c|c|c|c|}
\hline & & Design 1 & Design 2 & Design 3 & $\begin{array}{l}\text { Common single } \\
\text { layer hollow fibre }\end{array}$ \\
\hline \multirow{3}{*}{$\begin{array}{l}\text { Flow rate } \\
\text { ( } \mathrm{mL} / \mathrm{min})\end{array}$} & $\begin{array}{c}\text { Inner } \\
\text { polymeric } \\
\text { layer }\end{array}$ & N.A. & N.A. & 0.75 & N.A. \\
\hline & $\begin{array}{l}\text { Ceramic } \\
\text { layer }\end{array}$ & 16 & 7 & 16 & 7 \\
\hline & $\begin{array}{c}\text { Outer } \\
\text { polymeric }\end{array}$ & 1 & 4 & 1 & N.A. \\
\hline
\end{tabular}




\begin{tabular}{c|ccccc}
\hline & $\begin{array}{c}\text { layer } \\
\text { Bore fluid }\end{array}$ & 25 & 15 & 25 & 15 \\
\hline $\begin{array}{c}\text { Air gap } \\
(\mathrm{cm})\end{array}$ & & 0 & 25 & 0 & 25 \\
\hline
\end{tabular}

\subsection{Characterizations}

Morphologies and microstructures were characterized by scanning electron microscopy (SEM, JEOL JSM-5610 LV). The smallest size of open micro-channels in Design 1 and Design 2 was determined by gas-liquid displacement measurements with PoroLux 100 Porometer; For Design 3, the opening of the micro-channels cannot be determined by gas-liquid displacement due to the existence of the sponge-like layer; therefore mercury intrusion data was collected to obtain information of the pore structure. The mercury intrusion measurement was performed at absolute pressures of between $1.38 \times 103$ and $2.28 \times 108 \mathrm{~Pa}$ (Micromeritics Autopore IV) with an equilibration time of $10 \mathrm{~s}$ and assuming a mercury contact angle of $130^{\circ}$. The mechanical property was evaluated by an Instron materials testing system (Model 5544) with a $5 \mathrm{kN}$ load cell, using a three-point bending method where the samples were positioned onto a sample holder with a span of $30 \mathrm{~mm}$. 5 samples were used for each type of membrane with standard deviation of within 20 $\%$. The bending strength $\left(\sigma_{F}\right)$ was calculated using the following equation [21]:

$$
\sigma_{F}=\frac{8 F L D_{o}}{\pi\left(D_{o}{ }^{4}-D_{i}{ }^{4}\right)}
$$

where $F$ denotes the measured force when a fracture occurs $(\mathrm{N}), L$ is the fibre length $(\mathrm{m}), D_{o}$ and $D_{i}$ are the outer and inner diameters of the fibre $(\mathrm{m})$, respectively. Pure water permeation of Design 2 was evaluated via dead-end filtration tests under a 1 bar trans-membrane pressure, after being sealed into a stainless vessel using epoxy resin. The permeation tests were conducted with an outin mode. 3 samples were used for each sintering temperature with standard deviation of within 25 $\%$. The water permeation fluxes of the other two designs were not measured, as they were not designed for single-phase filtration purposes.

\section{Results}

\subsection{Cross-sectional morphology of the micro-structured hollow fibre membranes}

\subsubsection{Design 1}

The cross-sectional structure of Design 1's membrane precursor is displayed in Figures 3a and $3 \mathrm{~b}$. Here the outer layer consists of a polymer, and the inner layer the ceramic material. The micro-channels can be seen to initiate from the polymeric layer at the shell side (Figure $3 \mathrm{~b}$ ) upon contact with the non-solvent in the coagulant bath at zero air gap, and propagated through the ceramic layer into the weak non-solvent bore fluid, leaving an open lumen. The polymeric layer 
was then subsequently removed during the heat session. This design is achieved via the use of a triple-layered spinneret, to co-extrude a layer of ceramic suspension inside a polymeric layer. In this case the choice of bore fluid and solvent for the polymer dope are vital to ensure open microchannels at both the lumen and shell sides are achieved. The polymeric layer needs to be able to form intensive micro-channels that will have enough momentum to protrude through both layers. Therefore, NMP was chosen to solvate the PESf in both the outer polymeric and inner ceramic layers, according to previous literature [2]. The bore fluid was chosen to be a mixture of nonsolvent and solvent in order to reduce the precipitation rate at the lumen side, to prevent closure of the micro-channels in order to form an open lumen.

After calcination and sintering, the final membrane is left with open micro-channels at both the lumen and shell sides, as can be seen in Figure 3c-f. As the micro-channels are initiated from the shell side, their size at the outer layer is significantly smaller than the openings at the inner layer. The size and density of the openings at the shell side can be controlled via adjusting the polymeric, ceramic layers' and bore fluid composition as well as membrane thickness. There are many theories that different researchers have adopted for the source of these micro-channels, such as: the rapture of membrane surface [22], the growth of polymer-lean nuclei [23], viscosity gradient [24, 25], surface tension gradient [25-27], or the gradient of solidification and shrinkage rate along the interface [28]. As discussed in a previous study, the formation of the micro-channels may also be attributed to the Rayleigh-Taylor Instability, which occurs when there is an acceleration on the interface between two fluids of different masses, and arises from perturbing waves at the interface [2]. Possible sources of acceleration that can cause interfacial instabilities include the solvent and non-solvent exchange and polymer precipitation, which leads to the accelerated movement of the interface towards the polymer solution/ceramic suspension side. The general trends of micro-channel growth have been recorded, explained and quantitatively mimicked in this previous study, which explains the effect of different solvents in the ceramic suspension on the micro-channel lengths, shape and density. For Design 1, it can be therefore predicted that by using a solvent with a high mutual diffusion coefficient with the coagulant bath combined with a significant density gradient across the polymer and non-solvent interface, higher micro-channel densities at both the lumen and shell sides can be achieved. On the other hand, the polymeric layer thickness would also affect the micro-channel size and density. A thicker polymeric layer would mean larger micro-channel openings at the shell side, as the micro-channels would have had longer time to develop in both length and width before meeting the ceramic suspension. However this thickness cannot be too high such that the micro-channels lose all of their 
momentum before being able to protrude through the lumen. Design 1 can be used as a substrate from which additional membrane layers can be deposited upon, with much reduced mass transfer resistance due to the open-channelled structure. Furthermore, due to the long, cylindrical and non-tortuous micro-channels of Design 1, another possible application would be as a highefficiency mixing device to produce emulsions or dispersions of one liquid phase in another immiscible liquid phase.

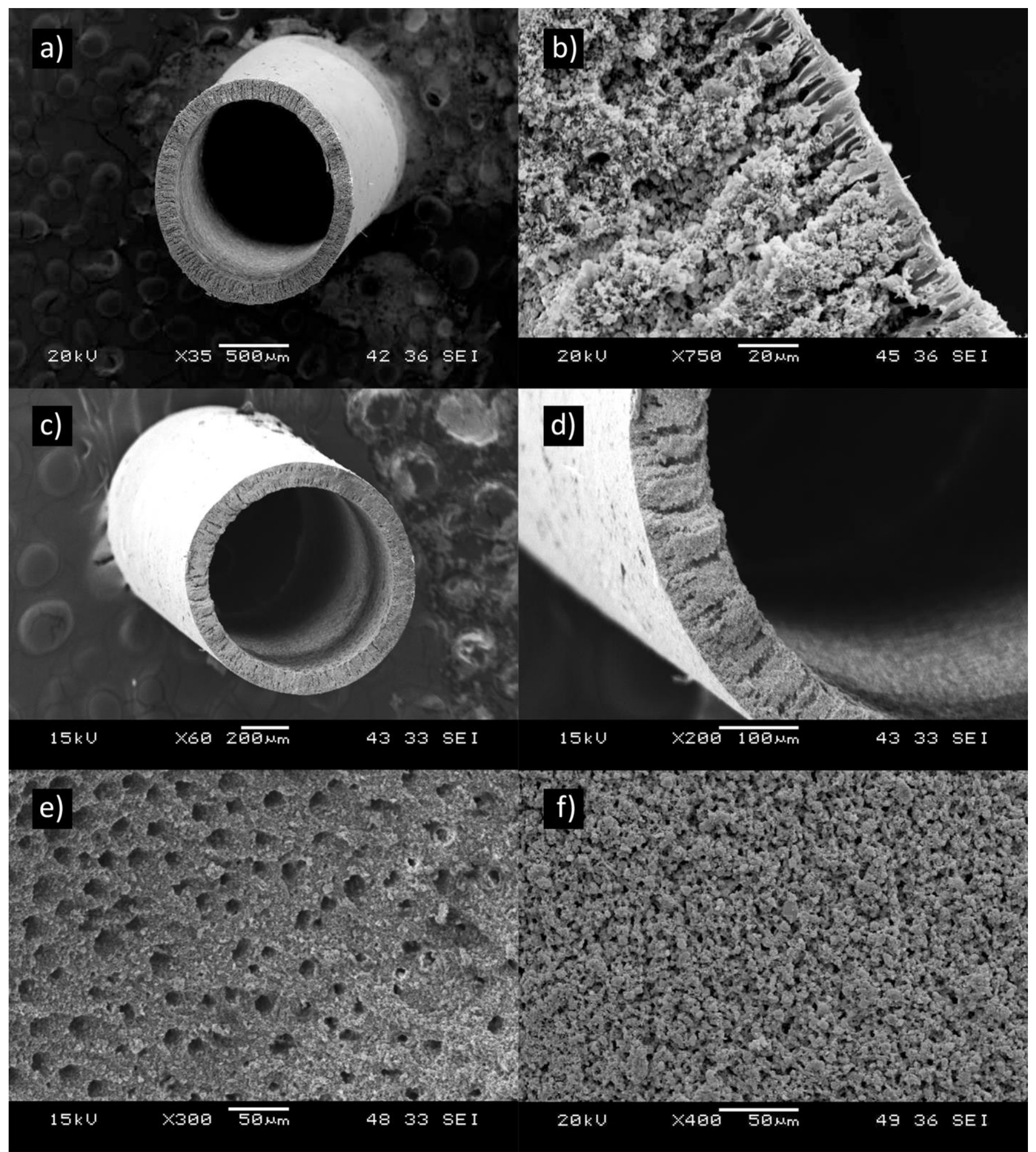

Figure 3 SEM cross-section images of the Design 1's dual-layered membrane precursor (a-b), 
sintered fibre at $1500{ }^{\circ} \mathrm{C}(\mathrm{c}-\mathrm{d})$ and the inner and outer surfaces of the sintered fibre at $1500{ }^{\circ} \mathrm{C}$ (ef), respectively

\subsubsection{Design 2}

Figure 4 displays the cross-sectional morphology of Design 2. From Figure $4 a$ and $4 b, a$ dual-layered membrane can be seen; this is the membrane precursor for Design 2. The inner layer consists of alumina particles, immobilised by the precipitated polymer binder, surrounded by an outer polymeric layer. All of the micro-channels originate from the lumen side upon contact with the non-solvent bore fluid, and propagates across the ceramic layer towards the shell, protruding through into the polymeric layer, as can be seen in the close up SEM (Figure 4b). After the heat treatment, the polymeric outer layer is removed, leaving an open outer surface. This type of design is created via the use of triple-layered spinnerets to simultaneously spin a ceramic layer inside a polymeric layer. During spinning, the lumen and shell sides will be in contact with the water non-solvent, and phase inversion will commence at both sides at different times by the use of a long air gap. The air gap gives time for the micro-channels to develop from the lumen before the outer polymeric layer comes into contact with the water bath, and here the choice of solvent in the polymer dope is vital to realise the designed structure. The outer polymeric layer needs to precipitate slowly enough for the micro-channels to break through at the ceramic suspension and polymeric layer interface, and to ensure that the polymer outer layer forms a continuous spongelike structure near the shell side. Therefore, in this case, TEP was chosen to solvate the PESf for the outer polymeric layer. A previous study has shown that no micro-channels are formed during phase inversion when TEP is used as the solvent, and its precipitation rate is slower than other common solvents [2]. The solvent chosen for dispersing the alumina particles and solvating the PESf for the inner layer is also important, as the acceleration of the interface at the lumen side needs to be high enough to initiate the micro-channels as well as to provide enough momentum for the micro-channels to propagate through the entire ceramic layer and into the polymeric layer. The theory behind the origin of the micro-channels can be found in the same previous study mentioned above [2]. Based on this previous study, DMSO was chosen as the solvent to facilitate the growth of long, regular and densely packed micro-channels. 


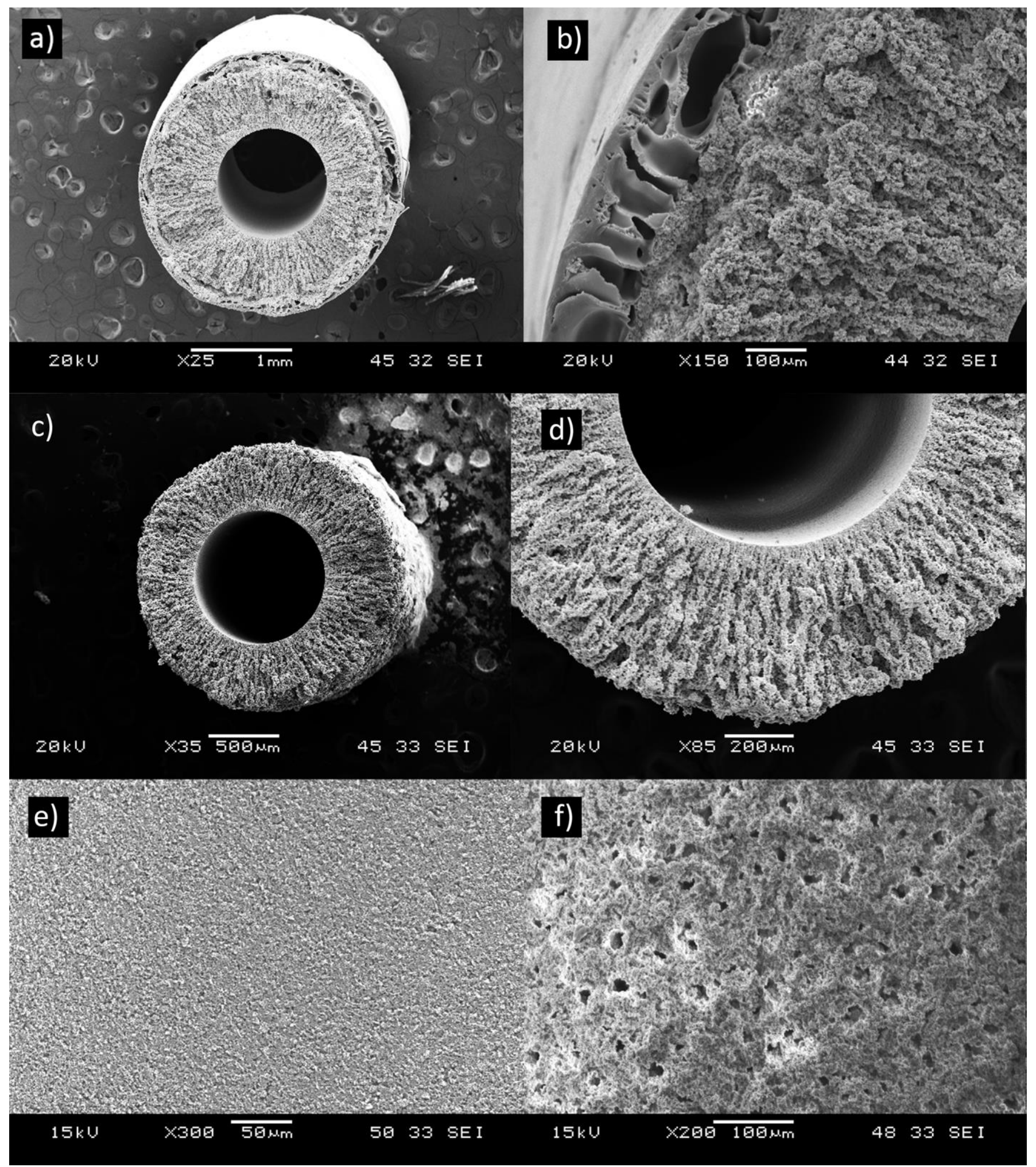

Figure 4 SEM cross-section images of Design 2's dual-layered membrane precursor (a-b), sintered fibre at $1500{ }^{\circ} \mathrm{C}$ (c-d) and the inner and outer surfaces of the sintered fibre at $1500{ }^{\circ} \mathrm{C}$ (e-f), respectively

Following debinding and sintering, the polymeric layer is eliminated and the ceramic inner layer is consolidated, as shown in Figure $4 \mathrm{c}$ and $4 \mathrm{~d}$. Here it can be seen that the membrane 
thickness is reduced significantly (from around $2580 \mu \mathrm{m}$ precursor diameter to $1870 \mu \mathrm{m}$ final diameter after sintering at $1500^{\circ} \mathrm{C}$ ). The lumen surface is dense and can thus act as a separation barrier, whereas the shell side surface consists of intensively arranged open micro-channels and together they reduce the mass transfer resistance of the membranes. The pore size and pore size distribution of the separation surface can be controlled using different suspension compositions as well as sintering conditions, and pore size can range from completely dense to micrometre-scaled. The size of the micro-channel openings at the shell side can be controlled by various factors. One method would be to change the composition of ceramic suspension and bore liquid to provide different driving forces for the initialisation and growth of the micro-channels, which may result in varied channel densities and channel sizes. Detailed explanations on the formation of the microchannels can be found in our previous study [2]. Another method would be to change the ceramic layer thickness, with thicker membranes leading to larger micro-channel openings, as the microchannels grow in both their length and lateral width across the radial direction. Due to the ease of access of these micro-channels from the shell side, catalysts or adsorbents can be easily deposited into these pockets of space, opening a broad range of different applications, such as water treatment hybrid systems, membrane micro-reactors, gas separation columns, etc.

\subsubsection{Design 3}

Figure $5 \mathrm{a}$ and $5 \mathrm{~b}$ display the cross-sectional morphology of the triple layered membrane precursor for Design 3, which has three layers: two polymeric layers sandwiching a layer of ceramic material. The inner polymeric layer could not be seen in the SEM diagram as the polymer shrinks and delaminates from the fibre immediately after the spinning process. This design is created via the use of a quadruple-layered spinneret (shown in Figure 2). During spinning, phase inversion will occur at both the lumen and shell sides, starting from the polymeric layers. In this case, it is desired for the micro-channels to be formed from the polymer sides and into the ceramic layer. Therefore, similar to Design 1, NMP was chosen for the polymeric and ceramic layers, and the micro-channels can be seen to originate from both the shell and lumen sides, breaking through to the ceramic layer, meeting in the middle.

Following debinding and sintering, a ceramic hollow fibre membrane with open microchannels at both the lumen and shell sides is formed (Figure 4c-f). The opening sizes of the microchannels at the inner layer are significantly smaller than the ones at the outer layer. The size of these micro-channels can again be controlled, using the methods mentioned for Designs 1 and 2. Furthermore, the sponge-like separation layer's pore size can also be tailored without significantly affecting the micro-channel sizes during sintering. Such a design could be used in applications such 
as a highly compact and efficient membrane micro-reactor for multiple reactions, whereby two catalytic reactions can take place in series in the catalyst-containing micro-channels at the different sides of the membrane.

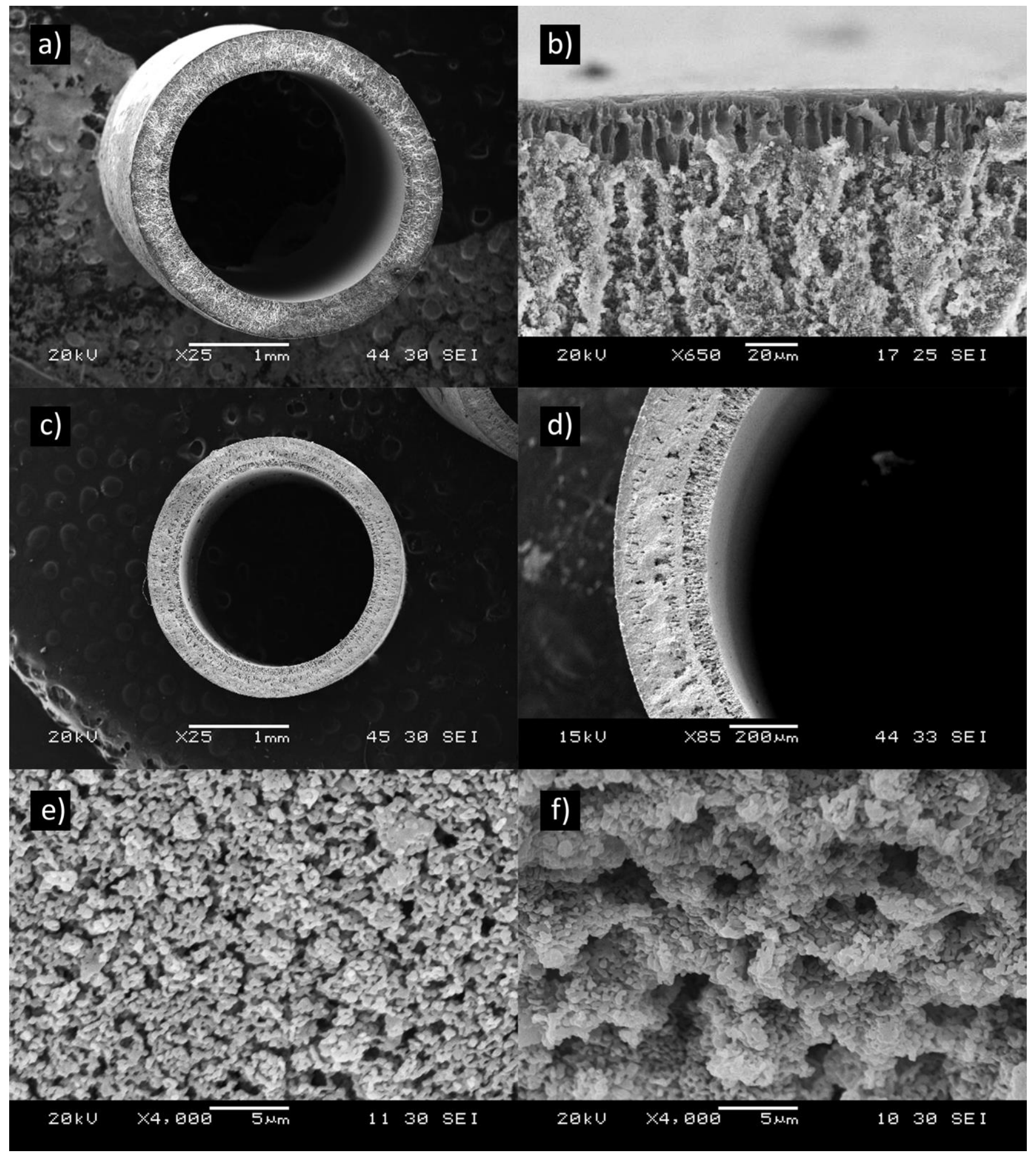

Figure 5 SEM cross-section images of Design 3's triple-layered membrane precursor (a-b), sintered

fibre at $1500^{\circ} \mathrm{C}$ (c-d) and the inner and outer surfaces of the sintered fibre at $1500{ }^{\circ} \mathrm{C}(e-f)$, respectively 


\subsection{Pore size, pore size distribution and micro-channel size}

Gas-liquid displacement porosimetry was used to probe information regarding the through pores of Designs 1 and 2. This method measures the smallest size of the channels; therefore the results give the opening size on the outer surface for Design 1 and the pore size on the inner separation surface for Design 2. Figure 6 reveals the size distribution of the micro-channel openings on the outer surface of Design 1. The graph shows a main peak at $3.41 \mu \mathrm{m}$ and a smaller peak at $1.65 \mu \mathrm{m}$, which may be attributed to different sets of micro-channels in the outer polymeric layer. From the SEM images (Figure 3e) the inner layer has much larger micro-channel openings of up to $40 \mu \mathrm{m}$ in diameter. For Design 2, Figure 7 reveals the pore size of the inner separation surface, which is at around $1 \mu \mathrm{m}$ and the micro-channel openings at the outer surface can be seen to range from $10 \mu \mathrm{m}$ to $40 \mu \mathrm{m}$ from SEM images (Figure 4f). Figure 8 shows the mercury intrusion result of Design 3, whereby the sponge-like layer pore size distribution and the size of the openings for Design 3 can be seen. The sponge layer pore sizes lie between $0.25-0.30$ $\mu \mathrm{m}$, and the bigger pore size distribution from 1-5 $\mu \mathrm{m}$, which peaked at $3.2 \mu \mathrm{m}$ can be attributed to the openings on the inner and outer surfaces. The result is concurrent with the SEM images, which confirms that the micro-channel openings for Design 3's inner layer mostly range between 1-2 $\mu \mathrm{m}$ (Figure 5e), whereas the outer layer micro-channel openings are in the range of between 3-5 $\mu \mathrm{m}$ (Figure $5 f)$.

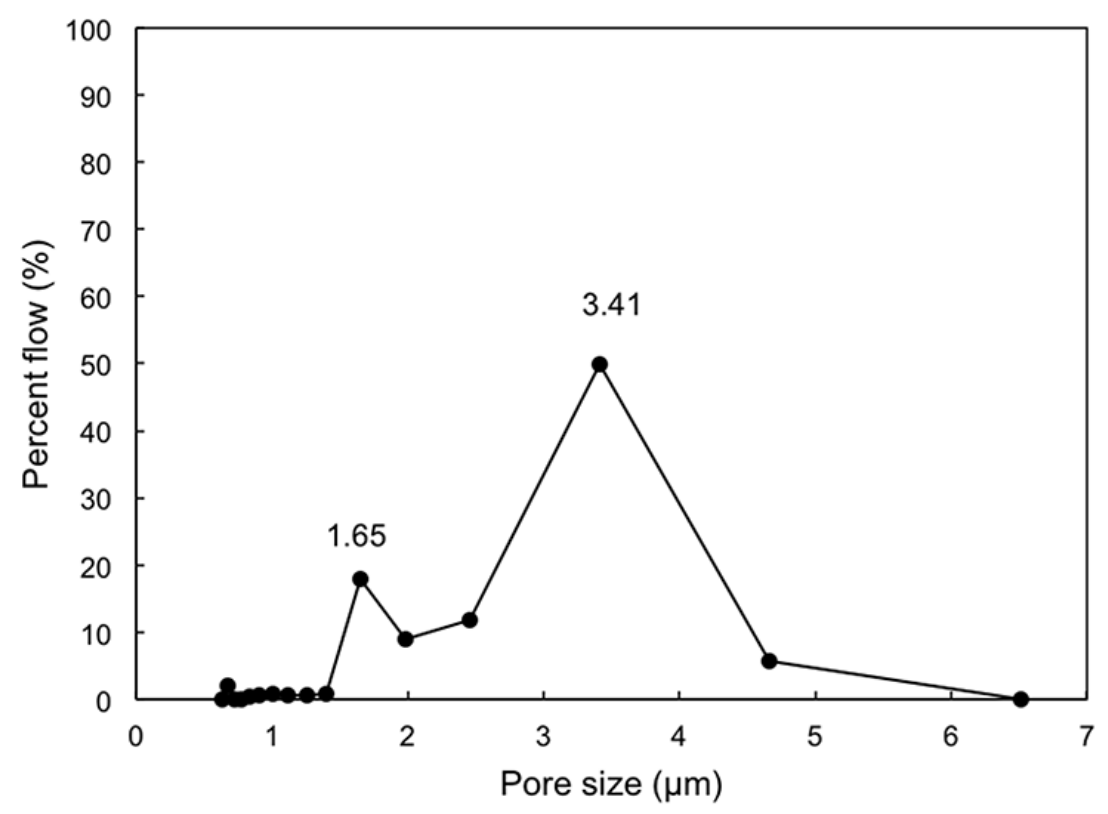

Figure 6 Gas-liquid displacement porosimetry data for membrane Design 1 


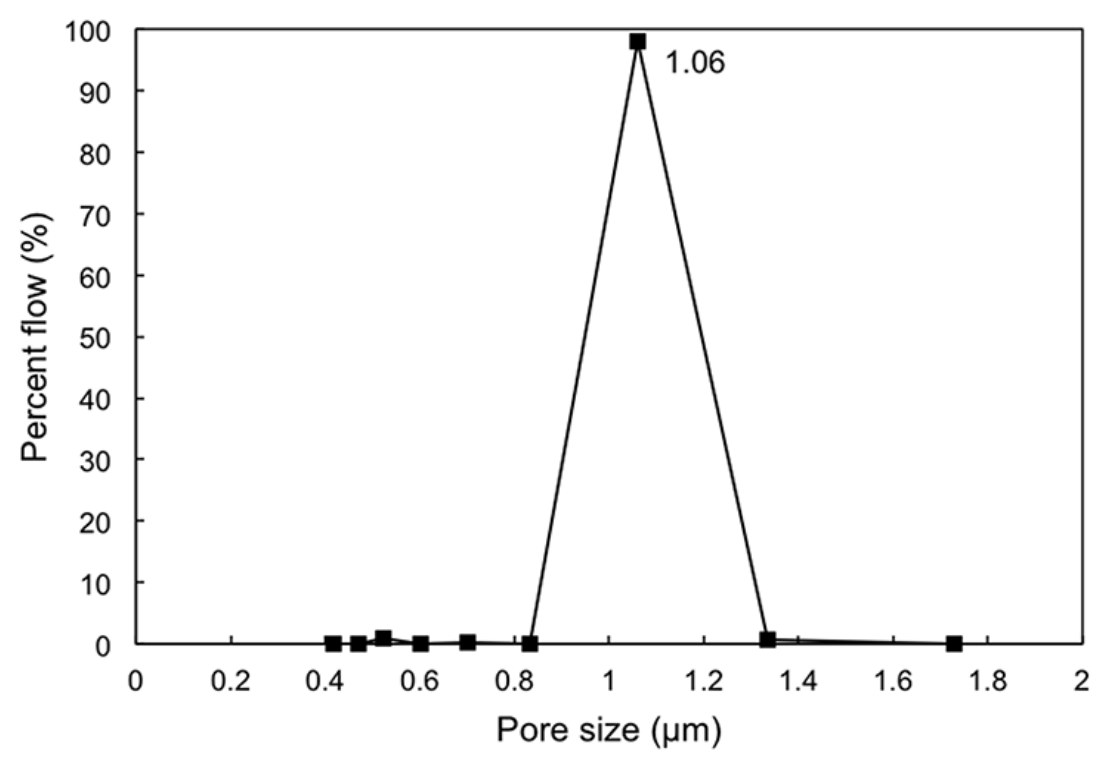

Figure 7 Gas-liquid displacement porosimetry data for membrane Design 2

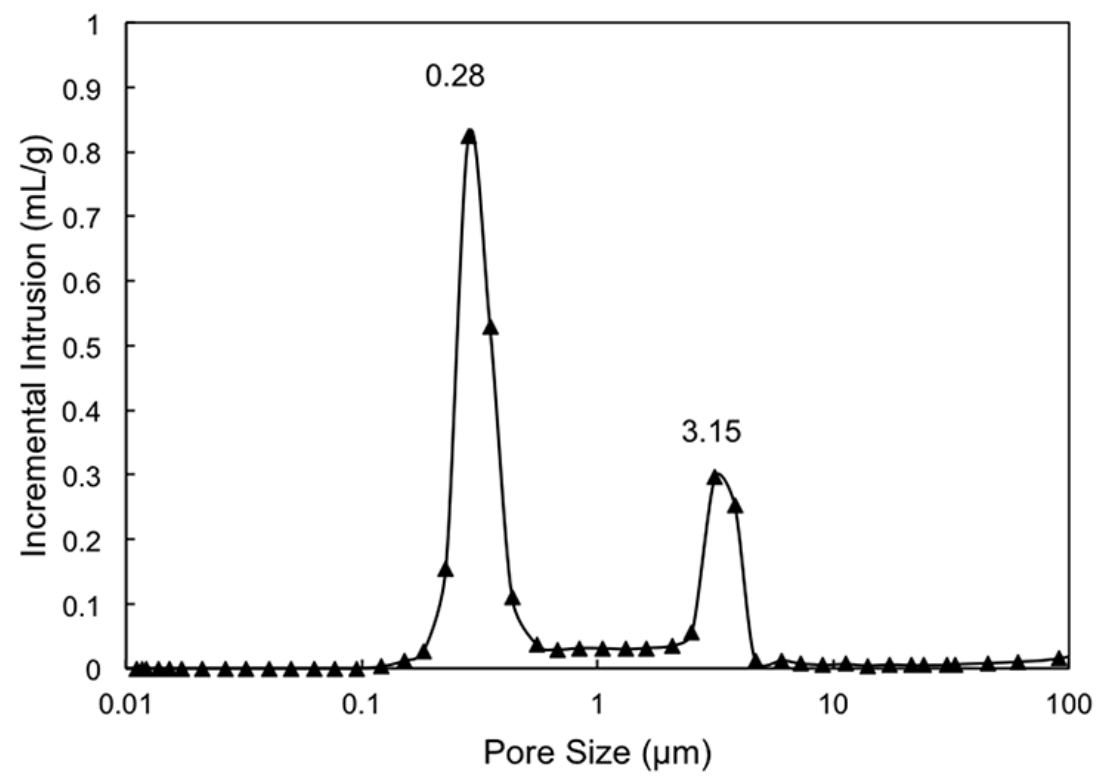

Figure 8 Mercury intrusion porosimetry data for membrane Design 3

\subsection{Water permeation}

In water treatment applications, it is desired for the clean water permeation rate to be as fast as possible. Design 2 has only one very thin separation layer, and its water permeation flux is evidently superior to common asymmetric hollow fibres fabricated in this study and also elsewhere [29], as can be seen in Table 3. Design 2 has fluxes that are about 60 times higher than an asymmetric hollow fibre membrane with dense inner and outer surfaces and sponge-like layers, reaching fluxes as high as $159,000 \mathrm{~L} / \mathrm{m}^{2} \mathrm{~h}$ bar. This is due to the ultra-thin effective separation layer in Design 2, whose average pore size is around $1 \mu \mathrm{m}$, providing sufficient 
selectivity for microfiltration applications. The long and open micro-channels provide the membranes with adequate mechanical stability to be used continuously under a trans-membrane pressure of 1 bar, which is sufficient for microfiltration. On the other hand, the pure water permeation fluxes of Design 1 and 3 were omitted, as their designs are not intended for singlephase microfiltration applications.

Table 3 Water permeation flux of Design 2 sintered at different temperatures under 1 bar transmembrane pressure operated under dead-end filtration mode

\begin{tabular}{c|ccc}
\hline \multirow{2}{*}{$\begin{array}{c}\text { Sintering } \\
\begin{array}{c}\text { Temperature } \\
\left({ }^{\circ} \mathrm{C}\right)\end{array}\end{array}$} & Design 2 & $\begin{array}{c}\text { Wommon asymmetric } \\
\text { hollow fibre }\end{array}$ & $\begin{array}{c}\text { Asymmetric } \\
\text { hollow fibre } \\
\text { from } \\
\text { literature[29] }\end{array}$ \\
\hline $\mathbf{1 4 5 0}$ & 159,000 & 2500 & 340 \\
$\mathbf{1 5 0 0}$ & 121,000 & 1872 & - \\
\hline
\end{tabular}

\subsection{Mechanical property}

Table 4 displays the 3-point bending strength of the 3 designs. It is apparent that the crosssectional morphology, composition of the different layers in the precursors, and sintering temperature can have dramatic influence on the membrane's mechanical stability. Design 1 has comparable bending strength to a typical asymmetrical ceramic hollow fibre formed by phase inversion in this study, especially at the lower sintering temperatures. Design 2 has the lowest bending strength out of all of the fibres fabricated in this study. Compared with Design 1, although both designs eliminate the sponge-like layer, the number of micro-channels and thus the porosity in Design 2 is significantly higher than Design 1's, and hence the mechanical property of Design 2 is much weaker, and this should be improved in future studies. Design 3 can be recognised to have the highest bending strength out of all of the fibres compared in this experiment at all sintering temperatures, due to fact that the design has a thick sponge-like layer, which give a strong support to the fibre. However, in general the mechanical stability is lower than others in literature, that have much thicker densely packed structures [29], and improving mechanical stability should be the focus of future works. 
Table 4 3-point bending strength of the 3 designs sintered at different temperatures

\begin{tabular}{c|ccccc}
\hline \multirow{2}{*}{$\begin{array}{c}\text { Sintering } \\
\text { Temperature } \\
\left({ }^{\circ} \mathrm{C}\right)\end{array}$} & Design 1 & Design 2 & Design 3 & $\begin{array}{c}\text { Common asymmetric } \\
\text { hollow fibre }\end{array}$ & $\begin{array}{c}\text { Asymmetric } \\
\text { hollow fibre } \\
\text { from } \\
\text { literature[29] }\end{array}$ \\
\hline $\mathbf{1 3 5 0}$ & 14.8 & 2.61 & 32.6 & 12.5 & - \\
$\mathbf{1 4 5 0}$ & 48.0 & 6.8 & 74.5 & 30.9 & 130 \\
$\mathbf{1 5 0 0}$ & 50.0 & 10.71 & 117.4 & 89.8 & 150 \\
\hline
\end{tabular}

4. Discussions

\subsection{Propagation of micro-channels at the two-layer interface}

The initiation and growth of micro-channels during phase inversion have been pointed out to be the consequence of interfacial instability [2]. We have studied the flat disc cases of alumina membranes and found that a quantitative prediction of the development of micro-channels can be achieved by using the Rayleigh-Taylor Instability theory. According to the R-T Instability theory, for the single layer cases, when water comes into contact with the polymer solution or ceramic suspension, the density difference and the interfacial acceleration would drive interfacial disturbances to grow quickly at certain wavelengths, and water streams penetrate into these growing points with a high initial speed, and the momentum of water streams may lead to the development of long and slim micro-channels in the membrane. In this study, whereby there were two higher density layers in contact with the lighter non-solvent, the interface between the two layers lies in the way of proceeding micro-channels, and various scenarios could be met and the propagation of micro-channels would occur differently.

In the case of Designs 1 and 3, the micro-channels grow from the polymeric layer into the ceramic layer, which means that the momentum of the water stream in the proceeding microchannels is partially dissipated in the polymeric layer first, before meeting the interface. The momentum must be adequate after passing the interface to push the micro-channels into the ceramic suspension, which has a higher viscosity and resistance to micro-channel growth. This means that if the thickness of the polymeric layer is increased, dissipation of the momentum in the polymeric layer will be higher. The remaining momentum that can work onto the ceramic suspension is smaller, and fewer micro-channels will have the adequate initial momentum to pass through to the ceramic layer, and the openings will be larger in size but more sparsely distributed. If the thickness of the polymeric layer is further increased, there will be no water streams with sufficient momentum to pass the ceramic layer, and no micro-channels would propagate through. 
In case of Design 2, micro-channels start from the ceramic layer and proceed towards the polymeric layer, and at the interface the viscosity and resistance decrease suddenly, making the front of micro-channels an easier way to out, and therefore the micro-channels cross over the interface easily, leaving big open pores on the surface of the ceramic layer when the polymer is removed after sintering.

\subsection{Potential applications of the three unique structured hollow fibres}

\subsubsection{Design 1}

As mentioned briefly in the results, the different micro-structures can be used for different applications, depending on the process and their different requirements. Design 1 has no active separation layer and therefore cannot be used directly for separation applications such as micro/ultrafiltration. Its unique structure consists of straight micro-channels that are open at both the lumen and shell sides, and their size and amount can be controlled during the spinning process. A potential application of this structural design would be membrane emulsification, a method that uses low pressure to force the dispersed phase to permeate through a porous membrane with a uniform pore size distribution into the continuous phase. This is much simpler, and requires lower energy requirements and less surfactant when compared with conventional methods that uses colloid mills, rotor-stator systems, and high pressure homogenizers [30]. Currently, membrane emulsification faces limitations due to their low fluxes, intrinsically due to the membranes available on the market. Another method is called micro-channel emulsification, which uses chips with micro-channel arrays made via etching, and can produce highly uniformsized droplets, but main drawback once again includes low production rates [31]. Design 1 has both the advantages of membrane and micro-channel emulsification, as it has a fairly uniform micro-channel size, and very low mass transfer resistance, as well as being able to form highly compact hollow fibre bundles. The dispersed phase can be pushed through the micro-channels from the lumen and enter the continuous phase to form the emulsions, as can be seen in Figure 9. As the micro-channel sizes can be tailored accordingly, a range of different sized droplets can potentially be formed. Furthermore, the membranes can be produced easily in large quantities, and hence scale-up would be simple by combining the membranes in modules and can potentially be used to mass-produce emulsions. 


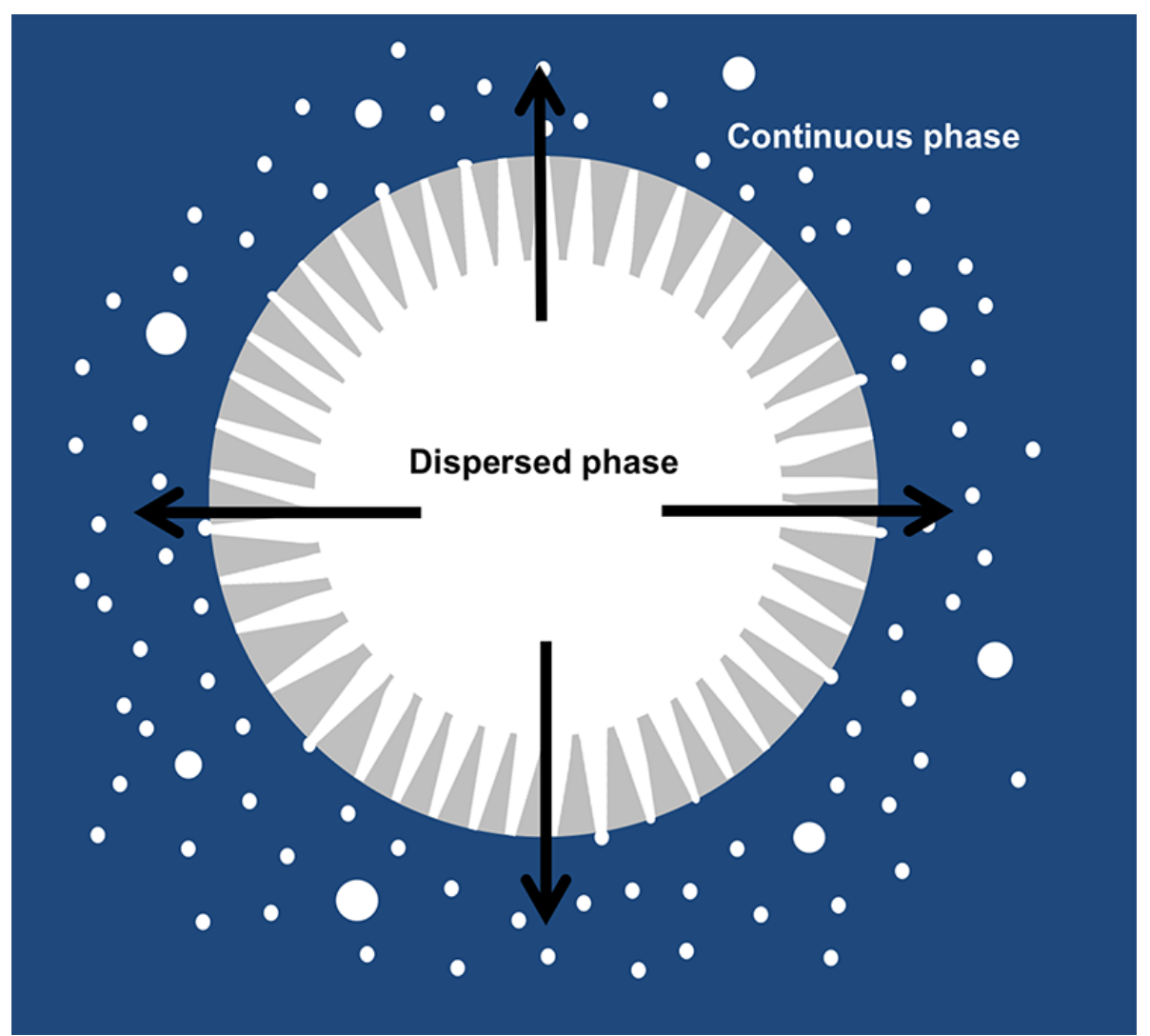

Figure 9 Schematic of a membrane emulsification process that can be realised with Design 1

\subsubsection{Design 2}

For Design 2, there is only one very thin separation layer at the lumen, and its advantages include very low mass transport resistance and extremely high geometric surface area. This makes them desirable for a wide range of applications, such as micro/ultrafiltration, micro-reactor, membrane hybrid systems, gas chromatography, etc. For micro/ultra-filtration, the membranes can be used on their own to provide selectivity against contaminants in wastewater such as sand and large particulates, colloids, bacteria, volatile organic components, etc. Furthermore, as the micro-channel densities are very high, these membranes provide an exceptional amount of accessible geometric surface area and volume, forming pockets in which other functional materials can be deposited. This opens up an extensive list of possible applications, such as: membrane micro-reactor with catalysts deposited into the micro-channels, one-step membrane hybrid system for heavy metal adsorption or a gas chromatography column by depositing adsorbents into the micro-channels, as depicted in Figure 10. The use of Design 2 membranes for the abovementioned applications will all potentially reduce a large amount of space required for the same amount of productivity, forming highly compact systems. 


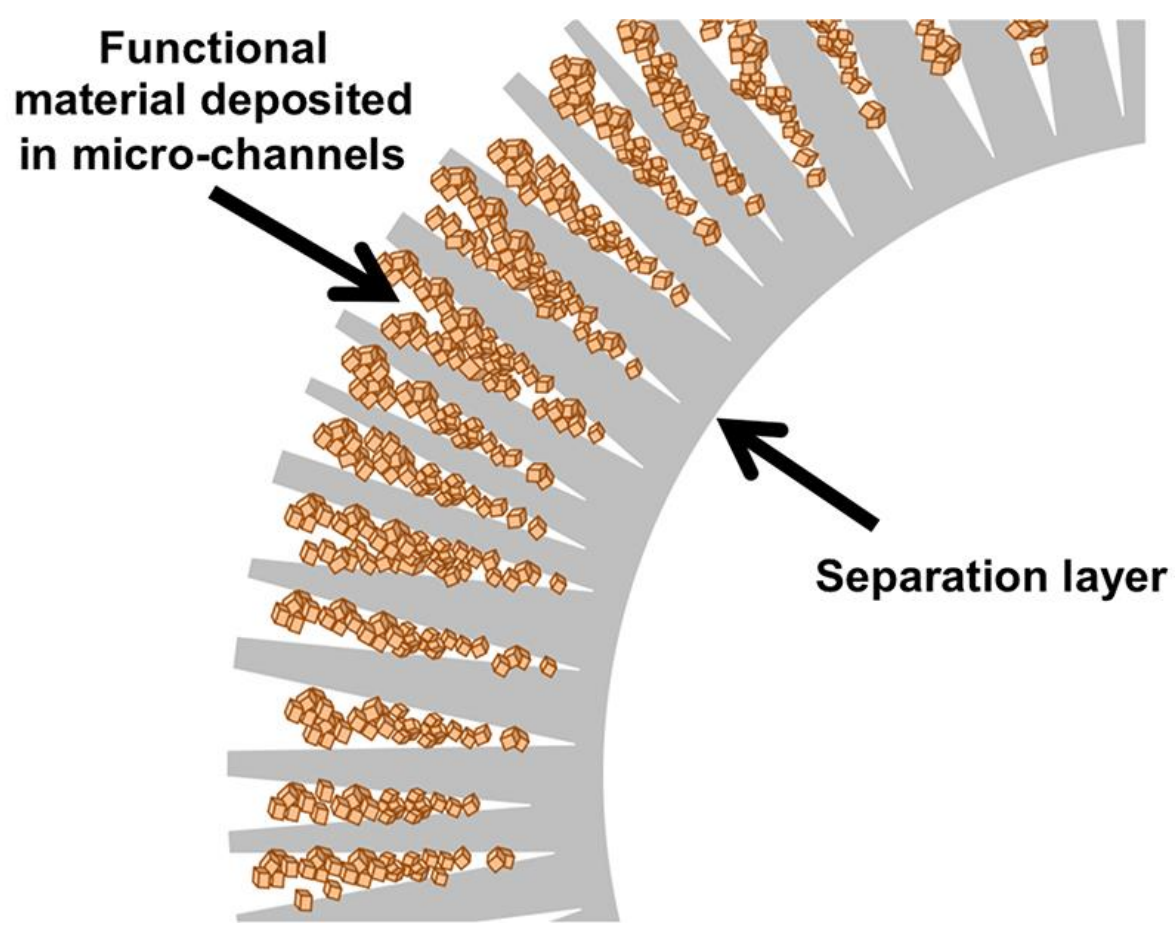

Figure 10 Schematic of membrane Design 2 with deposited functional material in the microchannels

\subsubsection{Design 3}

Design 3 has no smooth separation layer that is in direct contact with the feed, and therefore would not be additionally beneficial in micro/ultra-filtration processes as large contaminants can get deposited into the micro-channels, and would be difficult to clean. Instead, this design can possibly be used as a highly compact and efficient membrane micro-reactor for multiple reactions. As there are two sets of open micro-channels that are separated by a spongelike layer, two different reactions can take place in series at the different sides of the membranes. For example, Design 3 can potentially be used to combine the methanol reforming reaction with the water gas shift (WGS) reaction in one hollow fibre membrane reactor to produce hydrogen that is suitable for fuel cells, as illustrated in Figure 11. In this configuration, one side is packed with methanol reforming catalysts in the micro-channels, and when the feed of methanol and water vapour pass through the membrane, it will be converted to $\mathrm{H}_{2}, \mathrm{CO}_{2}$ and a small amount of CO. The products then flow into the packed WGS catalysts in the micro-channels of the other side and react with the water vapour fed from the other side to minimise the concentration of $\mathrm{CO}$, so that the produced hydrogen will be safe to use in polymer electrolyte membrane (PEM) fuel cells. Such a compact and highly efficient design would be especially useful to provide quality hydrogen for mobile devices, in which the space is very much limited.

And since the fabrication technique is applicable to other materials, the sponge-like layer in the middle of the Design 3 can be made to be selective to one of the products of the up-stream 
reaction, and take full advantages of the unique membrane structure. For example, if the membrane is made of a mixed ion and electron conducting (MIEC) material that only allow oxygen to permeate but not others, a decomposition reaction of an oxygen-containing compound and an oxygen-consuming reaction can be coupled seamlessly. A typical case for the up-stream reaction would be the catalytic decomposition of $\mathrm{CO}_{2}$, which produces $\mathrm{O}_{2}$ and $\mathrm{CO}$ at high temperatures with low equilibrium conversion rate; if the other side of the membrane is packed with catalysts for partial oxidation of methane (POM) or oxidative coupling of methane (OCM), which consumes oxygen from the other side through the middle separation layer, the equilibrium limit of the $\mathrm{CO}_{2}$ decomposition can be broken due to the removal of the oxygen product.

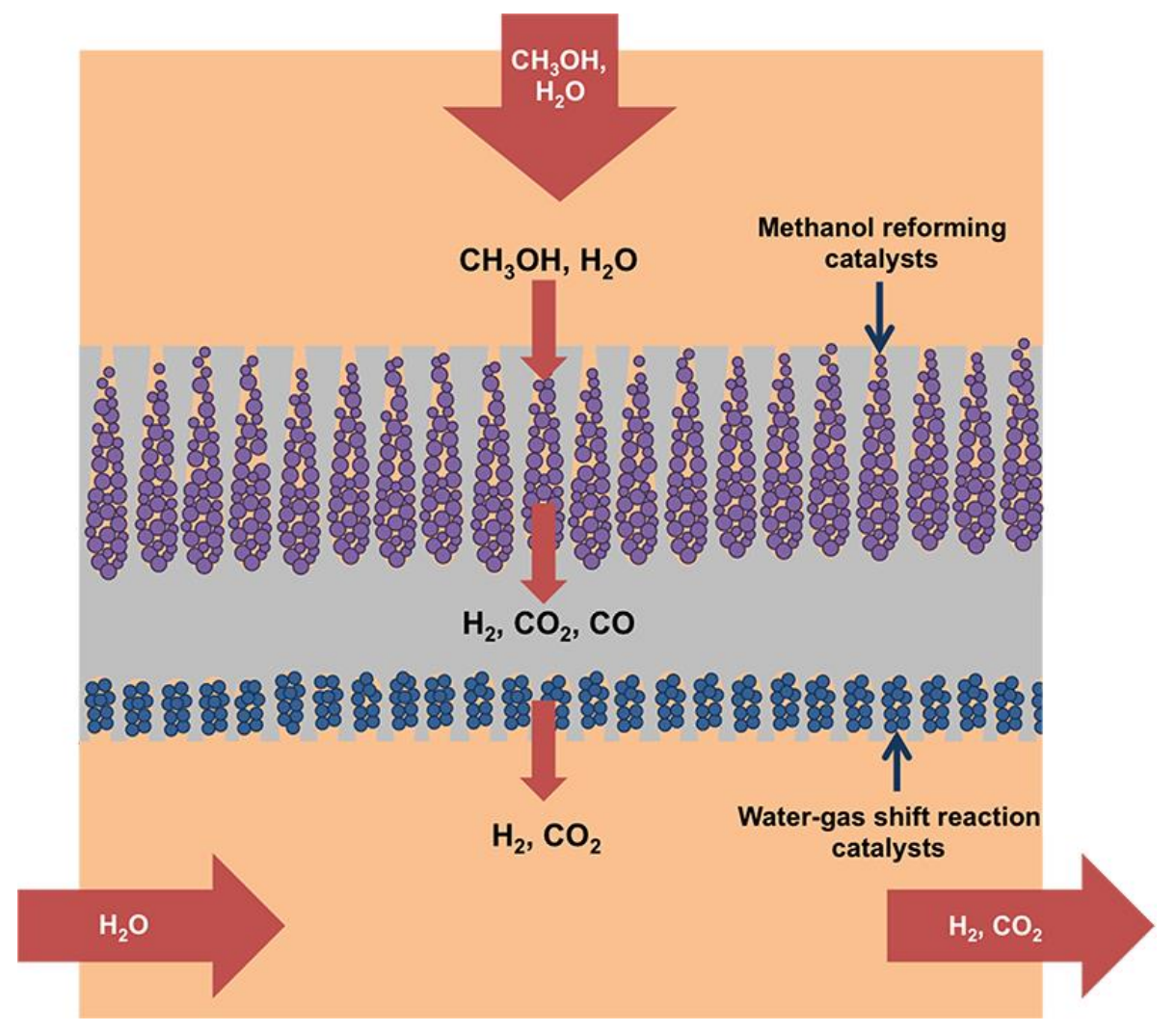

Figure 11 Schematic of a combined methanol reforming and water shift reaction process that can be realised with Design 3

\section{Conclusions}

Three new ceramic membrane structural designs have been performed and fabricated in this study, with long, cylindrical and non-tortuous micro-channels that can be arranged to be open at either the inner or outer surfaces, or both surfaces via a single-step co-extrusion method. Design 1, with long, straight and non-tortuous open micro-channels at both surfaces can potentially be used in membrane emulsification. Design 2 has open micro-channels on the outer surface that greatly reduce the mass transfer resistance of the membrane, due to the impressively 
reduced effective membrane thickness. This was evident in the pure water permeation flux of Design 2, which reached values as high as $159,000 \mathrm{~L} / \mathrm{m}^{2} \mathrm{~h}$ bar. Due to the very low mass transfer resistance combined with an exceptional amount of surface area offered by the micro-channels, Design 2 can potentially be used in a wide range of applications such as: micro-filtration for water treatment, membrane hybrid systems whereby adsorbents can be easily deposited into the microchannels for heavy metal removal, or as a gas chromatography column with adsorbents in the micro-channels for gas separation. Design 3 has open micro-channels on both the inner and outer surfaces, with a sponge-like layer in the centre. This design can potentially be used as a membrane micro-reactor for consecutive reactions, whereby the micro-channel at the different sides of the sponge-like layer can perform different reactions by the deposition of different catalysts. The micro-channel properties such as opening size as well as the selective layer pore size can be easily tailored according to the application by adjusting the spinning parameters. The main drawback of these new designs is the lower mechanical stability, which can be improved in future studies by increasing the overall membrane thickness whilst maintaining the very thin separation layer.

\section{Acknowledgements}

The authors gratefully acknowledge the research funding provided by EPSRC in the United Kingdom (Grant no EP/J014974/1) and B. Wang gratefully acknowledges the Marie Curie International Incoming Fellowships (Grant no. 627591). 
[1] M. Lee, Z. Wu, B. Wang, K. Li, Micro-structured alumina multi-channel capillary tubes and monoliths, Journal of Membrane Science, 489 (2015) 64-72.

[2] M. Lee, B. Wang, Z. Wu, K. Li, Formation of micro-channels in ceramic membranes - Spatial structure, simulation, and potential use in water treatment, Journal of Membrane Science, 483 (2015) 1-14.

[3] M. Lee, Z. Wu, R. Wang, K. Li, Micro-structured alumina hollow fibre membranes Potential applications in wastewater treatment, Journal of Membrane Science, 461 (2014) 3948.

[4] H. Huang, S. Cheng, J. Gao, C. Chen, J. Yi, Phase-inversion tape-casting preparation and significant performance enhancement of Ce0.9Gd0.101.95-La0.6Sr0.4Co0.2Fe0.803- $\delta$ dualphase asymmetric membrane for oxygen separation, Materials Letters, 137 (2014) 245-248.

[5] H. Fang, J.F. Gao, H.T. Wang, C.S. Chen, Hydrophobic porous alumina hollow fiber for water desalination via membrane distillation process, Journal of Membrane Science, 403-404 (2012) 41-46.

[6] H. Huang, J. Lin, Y. Wang, S. Wang, C. Xia, C. Chen, Facile one-step forming of NiO and yttrium-stabilized zirconia composite anodes with straight open pores for planar solid oxide fuel cell using phase-inversion tape casting method, Journal of Power Sources, 274 (2015) 1114-1117.

[7] J.-W. Zhang, H. Fang, J.-W. Wang, L.-Y. Hao, X. Xu, C.-S. Chen, Preparation and characterization of silicon nitride hollow fiber membranes for seawater desalination, Journal of Membrane Science, 450 (2014) 197-206.

[8] S. Zhuang, Y. Li, M. Zuo, X. Tan, B. Meng, N. Yang, S. Liu, Dense composite electrolyte hollow fibre membranes for high temperature CO2 separation, Separation and Purification Technology, 132 (2014) 712-718.

[9] X. Zhang, D.K. Wang, D.R.S. Lopez, J.C. Diniz da Costa, Fabrication of nanostructured TiO2 hollow fiber photocatalytic membrane and application for wastewater treatment, Chemical Engineering Journal, 236 (2014) 314-322.

[10] N.H. Othman, Z. Wu, K. Li, An oxygen permeable membrane microreactor with an in-situ deposited Bi1.5Y0.3Sm0.203- $\delta$ catalyst for oxidative coupling of methane, Journal of Membrane Science, 488 (2015) 182-193.

[11] A. Gouveia Gil, M.H.M. Reis, D. Chadwick, Z. Wu, K. Li, A highly permeable hollow fibre substrate for Pd/Al2O3 composite membranes in hydrogen permeation, International Journal of Hydrogen Energy, 40 (2015) 3249-3258.

[12] N.H. Othman, Z. Wu, K. Li, A micro-structured La0.6Sr0.4Co0.2Fe0.803- $\delta$ hollow fibre membrane reactor for oxidative coupling of methane, Journal of Membrane Science, 468 (2014) 31-41.

[13] X. Tan, N. Liu, B. Meng, S. Liu, Morphology control of the perovskite hollow fibre membranes for oxygen separation using different bore fluids, J. Membr. Sci., 378 (2011) 308318.

[14] N. Liu, X. Tan, B. Meng, S. Liu, Honeycomb-structured perovskite hollow fibre membranes with ultra-thin densified layer for oxygen separation, Sep. Purif. Technol., 80 (2011) 396-401.

[15] J. de Jong, N.E. Benes, G.H. Koops, M. Wessling, Towards single step production of multilayer inorganic hollow fibers, Journal of Membrane Science, 239 (2004) 265-269.

[16] J. Zhu, L. Jiang, T. Matsuura, New insights into fabrication of hydrophobic/hydrophilic composite hollow fibers for direct contact membrane distillation, Chemical Engineering Science, 137 (2015) 79-90.

[17] S. Bonyadi, T.S. Chung, Flux enhancement in membrane distillation by fabrication of dual layer hydrophilic-hydrophobic hollow fiber membranes, Journal of Membrane Science, 306 (2007) 134-146. 
[18] F.-J. Fu, S. Zhang, T.-S. Chung, Sandwich-structured hollow fiber membranes for osmotic power generation, Desalination, 376 (2015) 73-81.

[19] T. Li, Z. Wu, K. Li, Co-extrusion of electrolyte/anode functional layer/anode triple-layer ceramic hollow fibres for micro-tubular solid oxide fuel cells-electrochemical performance study, Journal of Power Sources, 273 (2015) 999-1005.

[20] S.M. Jamil, M.H.D. Othman, M.A. Rahman, J. Jaafar, A.F. Ismail, K. Li, Recent fabrication techniques for micro-tubular solid oxide fuel cell support: A review, Journal of the European Ceramic Society, 35 (2015) 1-22.

[21] S. Liu, K. Li, R. Hughes, Preparation of porous aluminium oxide (Al203) hollow fibre membranes by a combined phase-inversion and sintering method, Ceram. Int., 29 (2003) 875881.

[22] H. Strathmann, K. Kock, P. Amar, R.W. Baker, Formation Mechanism of Asymmetric Membranes, Desalination, 16 (1975) 179-203.

[23] C.A. Smolders, A.J. Reuvers, R.M. Boom, I.M. Wienk, Microstructures in Phase-Inversion Membranes .1. Formation of Macrovoids, J. Membr. Sci., 73 (1992) 259-275.

[24] B.F.K. Kingsbury, K. Li, A morphological study of ceramic hollow fibre membranes, J. Membr. Sci., 328 (2009) 134-140.

[25] R. Matz, Structure of Cellulose-Acetate Membranes .1. Development of Porous Structures in Anisotropic Membranes, Desalination, 10 (1972) 1-\&.

[26] C.V. Sternling, L.E. Scriven, INTERFACIAL TURBULENCE - HYDRODYNAMIC INSTABILITY, AlChE J., 5 (1959) 514-523.

[27] M.A. Frommer, R.M. Messalem, Mechanism of Membrane Formation .6. Convective Flows and Large Void Formation during Membrane Precipitation, Ind Eng Chem Prod Rd, 12 (1973) 328-333.

[28] P. Neogi, Mechanism of Pore Formation in Reverse-Osmosis Membranes during the Casting Process, Aiche J, 29 (1983) 402-410.

[29] G. Xu, K. Wang, Z. Zhong, C.-s. Chen, P.A. Webley, H. Wang, SiC nanofiber reinforced porous ceramic hollow fiber membranes, Journal of Materials Chemistry A, 2 (2014) 58415846.

[30] C. Charcosset, I. Limayem, H. Fessi, The membrane emulsification process-a review, Journal of chemical technology and biotechnology, 79 (2004) 209-218.

[31] G. Vladisavljević, I. Kobayashi, M. Nakajima, Production of uniform droplets using membrane, microchannel and microfluidic emulsification devices, Microfluidics and nanofluidics, 13 (2012) 151-178. 